\title{
ON THE PRESENCE OF UNCOMMON STYLAR GLANDULAR TRICHOMES IN ASTERACEAE: A STUDY IN KAUNIA R.M. KING AND H. ROB. (OXYLOBINAE, EUPATORIEAE)
}

\author{
Jessica N. Viera Barreto, ${ }^{1, *}$ Gisela Sancho, ${ }^{*}$ and Noelia Forte* \\ *División Plantas Vasculares, Museo de La Plata, Facultad de Ciencias Naturales y Museo, Universidad \\ de La Plata (UNLP), Paseo del Bosque s/n, CP 1900, Buenos Aires, Argentina \\ Editor: Bruce K. Kirchoff
}

\begin{abstract}
Premise of research. Glands on the styles of Asteraceae are uncommon. They are reported in Kaunia for the first time. Glandular trichomes of plants are involved in the synthesis of secondary metabolites. In Kaunia, secondary compounds with medicinal cytotoxic, antitumor activity, and sensitizing capacity were previously identified. In this frame, a deeper knowledge of glandular trichomes could shed light on the productivity of medicinal substances in Kaunia. The potential taxonomic and ecological value of stylar glandular trichomes in Kaunia is also explored together with trichome secretion phases throughout the floral developmental stages.
\end{abstract}

Methodology. Herbarium specimens and flowers fixed in FAA of 10 species of Kaunia were analyzed. Flowers in different developmental stages were studied to observe the secretory phases of stylar trichomes. A histochemical test was carried out to detect sesquiterpene lactones on stylar glandular trichomes.

Pivotal results. Glandular trichomes were detected on the ventral face of style branches in eight species of Kaunia in all floral stages analyzed. The stylar trichomes observed were mostly found in secretory or early postsecretory phases in the most immature floral stages. The histochemical test in stylar trichomes was positive for sesquiterpene lactones.

Conclusions. The presence of stylar glandular trichomes provides valuable new evidence for the identification and characterization of Kaunia. Within the Eupatorieae, the presence of stylar glandular trichomes could be interpreted as taxonomically valuable at the rank of genus. Our finding of sesquiterpene lactones is in agreement with the presence of Guaianolides and Germacranolides previously isolated in Kaunia. Apparently, the secretion of trichomes is completed before the opening of the corolla. The glands on styles of Kaunia could be the most internal barrier to herbivores that could flank outer floral structures during pollen and style development.

Keywords: compositae, morphology, secretory structures, sesquiterpene lactones, style.

\section{Introduction}

Glandular trichomes of plants are involved in the synthesis, storage, and emission of a broad array of secondary metabolites (e.g., Werker 1993, 2000; Bisio et al. 1999; Heinrich et al. 2002; Göpfert et al. 2005, 2009). Due to their important metabolic capacity, they may be considered true cell factories (Tissier 2012). Besides morphological, taxonomical, and ecological studies, the industrial uses of some trichome secretions (Duke 1994; Ramirez et al. 2012) and their potential as a defense barrier have recently boosted research even into the biosynthesis pathways that lead to these specialized metabolites (Göpfert et al. 2009; Tissier 2012).

In Asteraceae, glandular trichomes are widely found throughout the family tribes (e.g., Tetley 1925; Metcalfe and Chalk 1950; Fahn 1988; Anderberg et al. 2007; Ciccarelli et al. 2007). To-

${ }^{1}$ Author for correspondence; e-mail: jvierabarreto@fcnym.unlp .edu.ar.

Manuscript received April 2016; revised manuscript received July 2016; electronically published September 30, 2016. gether with secretory reservoirs (Lersten and Curtis 1988; Andreucci et al. 2008; Plos et al. 2011), they are responsible in the Asteraceae for synthesis of secondary metabolites postulated to play ecological roles as protection against insects and plant pathogens, attraction of pollinators or other beneficial insects, allelopathic effects, and protection against extreme environmental conditions (Langenheim 1994).

Chemically speaking, glandular trichomes of the Asteraceae are particularly rich in sesquiterpenoids (e.g., Seaman et al. 1980, 1982; Tateo et al. 2001; Heinrich et al. 2002; Göpfert et al. 2005; Bertea et al. 2006), and the presence of sesquiterpene lactones (e.g., Herz 1977; Emerenciano et al. 2001; Göpfert et al. 2005; Andreucci et al. 2008; Calabria et al. 2009) has also been widely documented in the family (e.g., Harborne 1977; Herz 2003; Taleb-Contini et al. 2004, 2007; Calabria et al. 2009).

With respect to the localization of glandular trichomes, in Asteraceae they are found on vegetative as well as floral structures. In floral structures, glandular trichomes are common on phyllaries, corollas, and cypselae (Anderberg et al. 2007). Glandular trichomes on anthers were less reported (Carpenter 1999; Robinson 1999; Göpfert et al. 2005). Stylar glandular 
trichomes are not common in the family, although they were found in a few genera in the Eupatorieae (King and Robinson 1987). While glandular trichomes on dorsal surfaces of style branches have been reported for some tribes (e.g., Heliantheae [King and Robinson 1987], Vernonieae [Via do Pico et al. 2016]), the presence of such glands on the ventral surface of the style branches is apparently unique to Eupatorieae (King and Robinson 1987). Recently, glands on the style branches were found in Kaunia (Eupatorieae) for the first time (J. N. Viera Barreto, unpublished manuscript). Kaunia includes ca. 11 species mainly distributed in Central Andean forests from Ecuador to Argentina, with one species distributed in Paraguay and southeastern Brazil (King and Robinson 1987). In Kaunia, glandular trichomes are also common on leaves, phyllaries, cypselae, and corollas of most of its species (King and Robinson 1987).

Some species of Kaunia (e.g., K. lasiophthalma Griseb. [Maldonado et al. 2014a, 2014b], K. rufescens (P.W. Lund ex DC.) R.M. King and H. Rob. [Rücker et al. 2001]) have been widely used in folk medicine. Recently, secondary compounds with medicinal activity have been identified in this genus (Rücker et al. 2001; Maldonado et al. 2014a, 2014b), and other compounds have shown strong sensitizing capacity (Rücker et al. 1997). Specifically, a wide array of sesquiterpenes has been isolated in Kaunia, including derivatives of these compounds that proved to have anticancer activity in vitro. Up to the present, the source of these secondary compounds in Kaunia has not been investigated, although, as occurs in other Asteraceae, glandular trichomes could be involved in sesquiterpene production. In the future, more exhaustive studies of the medicinal compounds of Kaunia could lead to crucial findings for fighting harmful diseases.

In addition to the potential taxonomic value of glandular trichomes at the generic level, the presence of such glands on the styles of Kaunia propounds interesting questions about their biological importance. Indeed, it has been suggested that secondary metabolites, such as sesquiterpene lactones found in glandular trichomes of other Asteraceae, may function as a chemical defense mechanism. Potentially, the study of the stylar glands and their secretory phases throughout the floral cycle could provide information about the biology of the species of Kaunia.

In this research we will study the morphology of the stylar glandular trichomes of the species of Kaunia, considering the stages of floral development in which they are present and the secretory phase of trichomes in each floral stage. We also will carry out a histochemical test to reveal the presence of sesquiterpene lactones.

We expect that stylar glandular trichomes will represent useful new evidence to identify Kaunia within the Eupatorieae. We also expect that the information obtained in this will help identify the secretory phases of stylar trichomes throughout the floral cycle, as well as assess the potential role of secretion as a chemical defense mechanism. Additionally, we assume that the outcomes of this study will shed light on the productivity of medicinal substances in Kaunia.

\section{Material and Methods}

\section{Plants}

For observation of stylar glandular trichomes, herbarium specimens of 10 of the 11 accepted species of Kaunia (appendix) were analyzed. We could not study K. hosanensis (B.L. Rob.) R.M. King \& H. Rob., since additional specimens, other than the type, were not found. Flowers of two species (K. camataquiensis and K. longipetiolata) collected in the field and fixed in FAA were additionally studied (appendix). Flowers of a total of 22 herbarium specimens were studied. Depending on the availability and the floral stages of herbarium specimens, one to five specimens of each species of Kaunia were selected in order to observe the presence, localization, and secretion phase of stylar glandular trichomes (two of $K$. camataquiensis, five of $K$. endyta, one of K. eucosmoides, two of K. gynoxymorpha, one of K. ignorata, two of K. lasiophthalma, three of K. longipetiolata, two of K. pachanoi, two of K. rufescens, and two of K. saltensis; appendix). In the flowers of Asteraceae, the male phase starts when the corollas are closed and pollen is released from the thecae to the anther tube. The male phase finishes after the pollen is exposed by style growth after the corolla opening (Erbar and Leins 1995). The female phase starts when the style is completely exserted and the stigmatic surface becomes fertile (Erbar and Leins 1995). To cover different stages of maturity, including male and female phases, flowers were selected from small buds to completely mature (these with opened corollas and totally exserted styles). We studied by species 48-60 flowers (and styles) at various stages of maturity to identify the trichome secretory phases in each floral stage. For K. ignorata, only completely mature flowers could be studied due to the absence of early floral stages in the available herbarium specimens.

\section{LM Observations}

Morphology, localization, and secretory phases of trichomes. Glandular trichomes usually synthesize phytotoxic secondary metabolites (especially sesquiterpene lactones in Asteraceae), which are produced in the trichome cells and secreted into an extracellular and subcuticular secretion storage space (subcuticular chamber) at the top of trichomes (Tateo et al. 2001; Göpfert et al. 2005; Andreucci et al. 2008). According to Göpfert et al. $(2005,2009)$; observation of the subcuticular chamber growth usually provides a reference of the presence and degree of secretion, and trichome cell content provides information about the senescence of cells, allowing an exact visual assessment of the trichome developmental stages. As proposed by Göpfert et al. (2005) for other types of floral glands of Asteraceae, to define the secretion phases of stylar glandular trichomes of Kaunia, we observed the content of the basal cells and the subcuticular chamber growth. For investigating the relationship between the trichome secretion phases and floral stages, flowers from small buds to fully mature (these with fully exserted styles) were studied.

To observe trichome phases and cell content, we rehydrated the removed flowers by immersion in a water bath at $25^{\circ}-30^{\circ} \mathrm{C}$ for $3 \mathrm{~d}$. Flowers were dissected and styles separated and mounted on slides for trichome observation. Some flowers and styles were bleached with sodium hypochlorite $(50 \%)$, washed, and stained in 2\% safranin (Johansen 1940) for additional observations. Descriptive terminology for trichomes follows Ramayya (1962). LM observations and photographs of herbarium samples were taken on a Nikon Eclipse E 200 microscope equipped with a camera lucida and a Nikon TV Lens $\times 0.55$ DS digital camera. 
Histochemical test for detecting sesquiterpene lactones. Herbarium specimens of two selected species of Kaunia (K. longipetiolata and K. camataquiensis), in which the presence of stylar glands was confirmed by LM observations, were used for the histochemical test. Histochemical analyses on herbarium specimens have yielded successful results in other Asteraceae (Hernández et al. 2015). Several flowers of each species were dissected, separating the styles. The styles were reconstituted as indicated above, bleached with sodium hypochlorite $(50 \%)$, and washed twice with sterilized distilled water. For detection of sesquiterpene lactones, the test was conducted by placing samples on slides and adding concentrated sulfuric acid dropwise (Geissmann and Griffin 1971; Andreucci et al. 2008). LM observations and photographs of herbarium samples were taken with the same equipment as above.

SEM observations. For conventional SEM observations, styles of herbarium specimens were taken. The samples were rehydrated as indicated above, fixed in FAA, dehydrated in an increasing ethanol series $(75 \%, 80 \%, 90 \%, 95 \%$, and $100 \%$ ), and critical-point dried (in a BAL-TEC CP30 critical point) with carbon dioxide in $100 \%$ ethanol and then were mounted on stubs with double-sided adhesive tape, followed by gold-palladium sputter-coating. The observations were carried out with a JEOL/JSM-6360 LV microscope at the Museo de La Plata, Argentina.

For environmental SEM (ESEM) observations, flowers from herbarium specimens were rehydrated as indicated above and used without additional pretreatment, at $90 \%$ relative humidity and $625.5 \mathrm{~Pa}$ (4.7 torr) in the ESEM chamber. The samples were scanned and photographed in a FEI/Quanta 200 microscope at the School of Engineering of the University of La Plata, Argentina.

\section{Results}

Morphology, localization, and phases of the trichome secretion. Glandular stylar trichomes were detected in 8 of the 10 surveyed species of Kaunia (K. camataquiensis, K. endyta, K. eucosmoides, K. ignorata, K. lasiophthalma, K. longipetiolata, K. pachanoi, K. rufescens). In K. saltensis and K. gynoxymorpha stylar glandular trichomes were not found. The observed trichomes correspond with Ramayya's (1962) glandular biseriate subtype $\beta$. They have a distinct simple foot and a body not differentiated into stalk and head. The body has two rows of five or six cells broader than higher (fig. $1 A, 2 A$ ). The apical cells are somewhat larger than the lower ones and have a thin cuticle that lifts to form a large subcuticular chamber for the secretory products (fig. 1A). When mature, the subcuticular chamber is globose and completely surrounds the apical cells (fig. 1A). Under the SEM and the ESEM, we found structures on the surface of the cuticle surrounding the chamber that we interpret as micropores (fig. $2 A, 2 B$ ). In other cases, the cuticle was disrupted probably as part of the secretion process. Glandular trichomes were found in numbers of 1 to 25 on both style branches and always on the ventral surface (figs. $1 B, 2 B-2 D$ ). In half of the cases ( 4 of 8 species), these glandular trichomes are mostly exclusively placed between the two marginal stigmatic bands in which the fertile papillae are grouped (fig. 2D). In a few cases ( 2 of 8 species), the trichomes are between the area with the stigmatic bands and the base of the sterile appendages (section of the style branch above the stigmatic bands) or mostly on the sterile appendages of style branches ( 2 of 8 species). Usually, these same patterns were observed on styles along all the floral stages.

In the secretion process of stylar trichomes of Kaunia, we identified four main phases: (1) presecretory phase (trichome
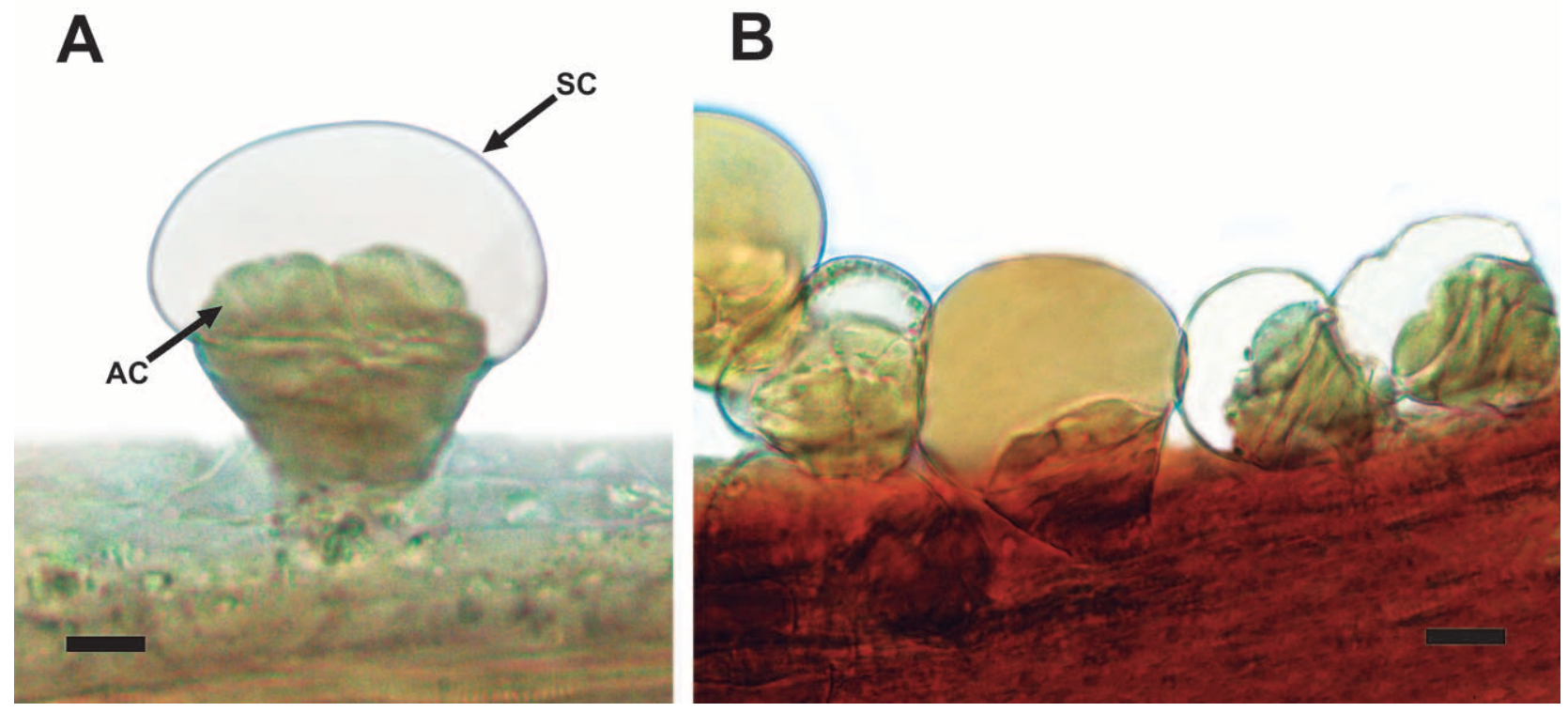

Fig. 1 Morphology of stylar glandular trichomes of Kaunia. A, Stylar glandular trichome showing the basal cells, the apical cells somewhat larger than the lower ones, and the subcuticular chamber; arrows indicate subcuticular chamber (SC) and apical cell (AC). B, Ventral face of style branch showing a group of glandular trichomes. Photographs: K. longipetiolata, B Peyton 1144 (F). Scale bars: $A=12 \mu \mathrm{m}, B=18 \mu \mathrm{m}$. 

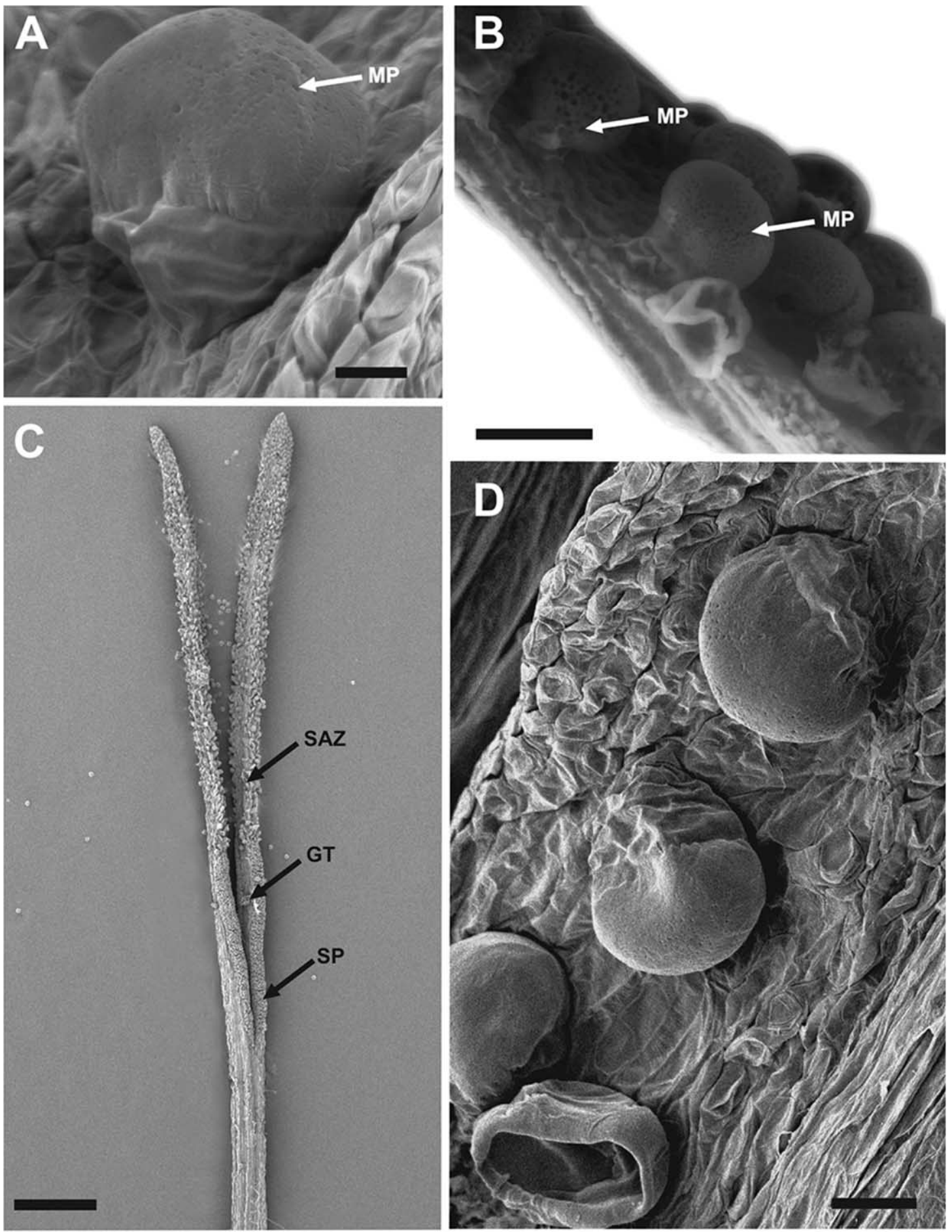

Fig. 2 SEM and ESEM images of morphology and localization of stylar glandular trichomes of Kaunia. A, SEM image of glandular trichome showing globose subcuticular chamber; arrow indicates structure interpreted as a micropore (MP). $B$, ESEM image of glandular trichomes; arrows indicate structures interpreted as micropores (MP). C, SEM image of style showing a glandular trichome (GT), the stigmatic papillae (SP), and the sterile apical appendage zone (SAZ). D, SEM image of ventral surface of style branch showing glandular trichomes between the stigmatic bands. Photographs: K. longipetiolata, Peyton 1144 (F). Scale bars: $A=10 \mu \mathrm{m}, B=50 \mu \mathrm{m}, C=250 \mu \mathrm{m}, D=20 \mu \mathrm{m}$. 

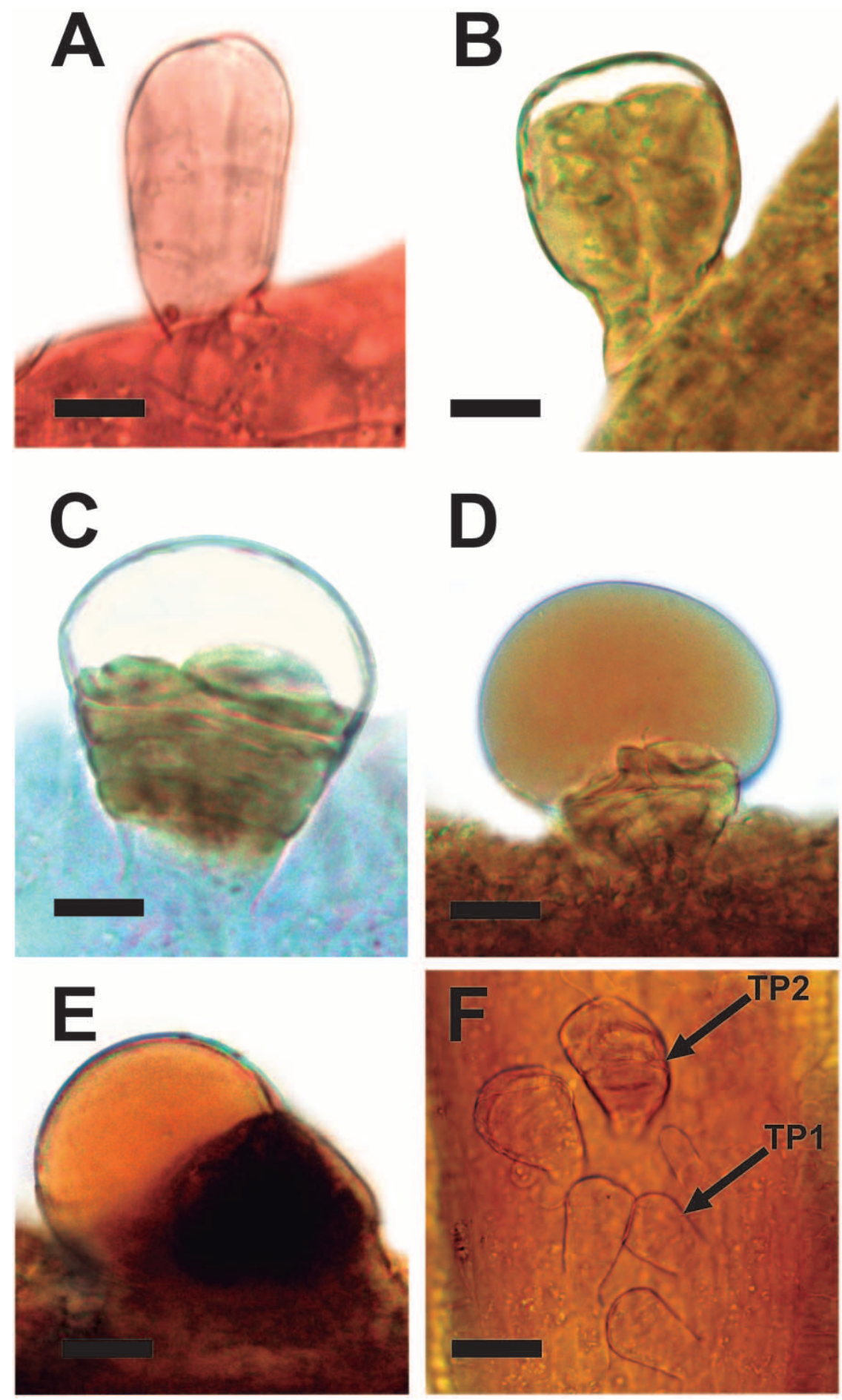

Fig. 3 Secretory phases of the stylar glandular trichomes of Kaunia. A, Trichome in presecretory phase, basal cells with light-colored content, subcuticular chamber absent. $B, C$, Trichomes in secretory phase showing different degrees of subcuticular chamber growing. $D$, Trichome in early postsecretory phase showing basal cells, which begin to collapse, and a fully expanded subcuticular chamber. E, Trichome in postsecretory phase showing a fully expanded subcuticular chamber and fully collapsed basal cells. $F$, Style of floral stage 0 showing trichomes in phases 1 (presecretory) and 2 (secretory); arrows indicate trichome phase 1 (TP1) and trichome phase 2 (TP2). Photographs: K. longipetiolata, B Peyton 1144 (F). Scale bars: $A=8 \mu \mathrm{m}, B=10 \mu \mathrm{m}, C=12 \mu \mathrm{m}, D=15 \mu \mathrm{m}, E=14 \mu \mathrm{m}, F=24 \mu \mathrm{m}$. 
without subcuticular chamber; fig. $3 A$ ); (2) secretory phase, in which we found different degrees of subcuticular chamber expansion (fig. 3B, 3C); (3) early postsecretory phase (the subcuticular chamber is fully expanded and the basal cells begin senescence; fig. $3 D$ ); (4) postsecretory phase (the subcuticular chamber, entire or disrupted, is fully expanded and the stalk cells are entirely degraded; fig. $3 E$ ). Trichomes in phase 1 were difficult to observe due to their small size and the translucent content of the cells.

In the range from small buds to fully mature flowers, four stages (stages 0-4; table 1; fig. 4) resulted, representative of the main steps of the floral cycle, and were taken as reference to correlate with stylar trichome secretion phases. The four floral stages were defined based on corolla, anther, and style features and pollen development and position (see table 1). We found that for all species in floral stage 0 , most of the glandular trichomes of styles possessed the subcuticular chamber fully covering the two apical cells. Commonly, the basal cells of trichomes in floral stage 0 began senescence (phase 3 of secretion), or the subcuticular chamber (entire or disrupted) was fully covering the top of the trichome, but the basal cells were entirely degraded (phase 4 of secretion). Sporadically (e.g., in K. longipetiolata and K. rufescens), trichomes in phase 1 (i.e., presecretory phase; the subcuticular chamber is absent) and phase 2 (i.e., secretory phase; the subcuticular chamber is growing although it does not completely cover the apical trichome cells) were found on floral stage 0 (fig. $3 F$ ), together with other trichomes in phases 3 and 4. Table 2 summarizes the results of LM observations of stylar glandular trichomes by species.

Histochemical test for detecting sesquiterpene lactones. The secretory products of stylar glandular trichomes stain positively for sesquiterpene lactones (fig. 5) in both tested species. Depending on the trichome secretion phase, only the trichome cells or both trichome cell and subcuticular chamber content responded positively for sesquiterpene lactones. Usually the subcuticular chamber showed stronger positive stain than basal cells.

\section{Discussion}

Morphology and taxonomic value of stylar glandular trichomes. Stylar glandular trichomes in Kaunia were reported and described herein for the first time. The glandular trichomes found on styles of Kaunia correspond to the "globular" morphology defined by Ciccarelli et al. (2007), which is common in Asteraceae. Apparently, disruption of the cuticle surrounding the chamber allows the secretion release as occurs in glandular trichomes of other members of the family (Andreucci et al. 2008; Plos et al. 2011). Structures on the cuticle that we interpret as micropores were found in stylar trichomes of Kaunia with two different preparation methods (for SEM and ESEM observations). Micropores on the cuticular surface of glandular trichome cells were reported in other Asteraceae as Inula L. (Werker and Fahn 1981), but their presence is unusual in this family, and further study is necessary to investigate their function in Kaunia.

Although not present in all species (they are absent in two species, K. saltensis and K. gynoxymorpha), the glandular trichomes on styles provide valuable additional evidence for the identification and characterization of Kaunia. Indeed, although Kaunia was defined by a complex of characters and microcharacters (King and Robinson 1980), King and Robinson (1987) pointed out the general lack of specialization of some features of styles and corolla lobes of this genus. Thus, the presence of stylar glandular trichomes in Kaunia appears as a useful additional generic diagnostic character.

According to our study, most of the trichomes are found between the stigmatic bands, and in a few cases they are either at the base of the sterile appendages or throughout the sterile appendage of style branches. Up to the present, stylar glandular trichomes were detected in a few genera of Eupatorieae. For instance, they were found in Sartorina R.M. King and H. Rob. (Fleischmanninae), which has glands on the stylar shaft; in Stylotrichium Mattf. (Gyptidinae) and some species of Mikania Willd. (Mikaniinae), which have glands on the dorsal surface of style branches; and in Neobintonia R.M. King and H. Rob. (Critoniinae) and Decachaeta DC. (Hebecliniinae), which have glands on the ventral surface of style branches (King and Robinson 1987). Although not fully studied in all genera, the presence of stylar glandular trichomes appears scattered in different subtribes. Apparently, the presence of glandular trichomes on styles, in general, and their presence on the ventral surface of branches, in particular, arose independently and probably in parallel with the evolution of Eupatorieae. Thus, the presence of stylar glandular trichomes could be taxonomically valuable at the rank of genus, although its value for defining monophyletic groups should be carefully studied in a tribal and subtribal context.

Secretory phases of stylar glandular trichomes and nature of secretion. In the Asteraceae, only a few studies have related the secretion phases of glandular trichomes to floral developmental stages (e.g., Ferreira and Janick 1995; Göpfert et al. 2005, 2009). We carried out a study taking into account four main floral stages taken from the whole floral cycle to correlate by indirect evidence with the phases of trichome secretion. The trichomes were found in different floral stages, ranging from a very small bud (floral stage 0) to mature flowers (with open corollas and fully exerted styles; floral stage 4). Unlike Göpfert et al. (2005), we found trichomes in different

Table 1

Floral Stages Taken as Reference to Correlate with Stylar Trichome Secretory Phases (see Fig. 4)

\begin{tabular}{lllll}
\hline Floral stage & Corolla & Anther thecae & \multicolumn{1}{c}{ Pollen } \\
\hline Stage 0 & Closed & Closed & Enclosed in the thecae & Enclosed in the corolla \\
Stage 1 & Closed & Dehisced & Enclosed in the synantherous cavity & Enclosed in the corolla \\
Stage 2 & Open & Dehisced & Released & Partially exserted (1-2 mm) \\
Stage 3 & Open & Dehisced & Shed & Completely exserted \\
\hline
\end{tabular}




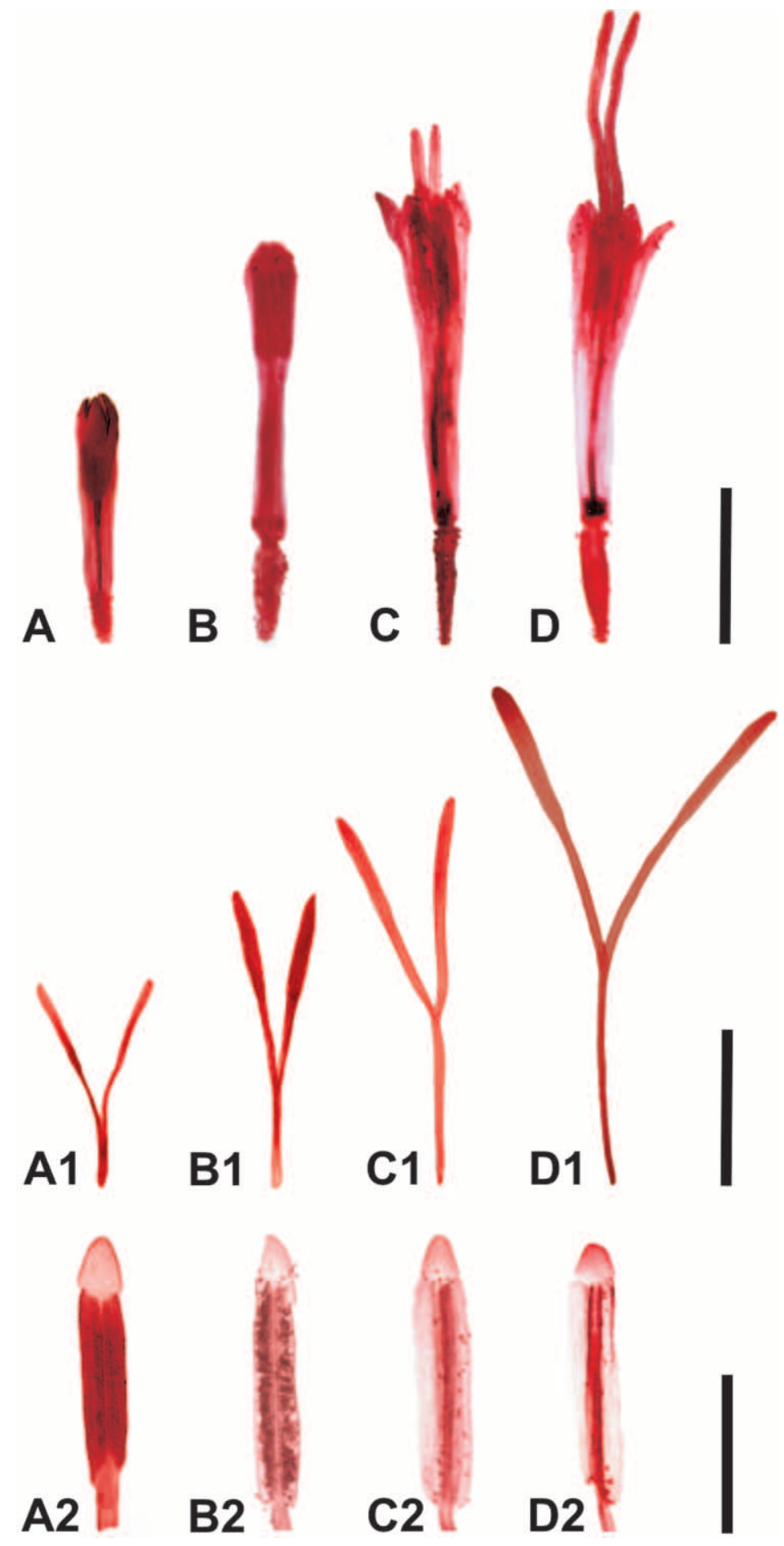

Fig. 4 Floral stages taken as reference to correlate with stylar trichome secretory phases. $A-A 2$, Floral stage 0 showing the closed corolla (style enclosed), growing style, and closed anther thecae; pollen enclosed inside the thecae. B-B2, Floral stage 1 showing the closed corolla (style enclosed), growing style, and dehisced anther thecae; pollen partly released. $C-C 2$, Floral stage 2 showing the open corolla, growing styles partially exserted (1-2 mm), and dehisced anther thecae; pollen partly released. $D-D 2$, Floral stage 3 showing the open corolla; developed and completely exserted styles; and dehisced, almost empty anther thecae. Flowers, styles, and anthers are stained with safranin. Scale bars: $A-D, A 1-D 1=2.5 \mathrm{~mm}$; $A 2-$ D2 $=9.5 \mathrm{~mm}$. 
Table 2

Results of LM Observations of Stylar Glandular Trichomes by Species

\begin{tabular}{lcclc}
\hline Species & Floral stage & Trichome phase & Trichome position & No. trichomes per style branch \\
\hline K. camataquiensis & 0 & 3 & Most in SAZ & $7-14$ \\
K. camataquiensis & $1-3$ & 4 & Most in SAZ & $7-14$ \\
K. endyta & 0 & 3 and 4 & STZ & $1-3$ \\
K. endyta & $1-3$ & 4 & STZ & $1-3$ \\
K. eucosmoides & 0 & 3 and 4 & STZ & $2-9$ \\
K. eucosmoides & $1-3$ & 4 & STZ & $2-9$ \\
K. gynoxymorpha & $0-3$ & ABS & ABS & ABS \\
K. ignorata & 3 & 4 & STZ and SAZ & 13 \\
K. lasiophthalma & 0 & 3 & STZ & $2-4$ \\
K. lasiophthalma & $1-3$ & 4 & STZ & $2-4$ \\
K. longipetiolata & 0 & $1-4$ & STZ and base of SAZ & $5-25$ \\
K. longipetiolata & $1-3$ & 4 & STZ and base of SAZ & $5-25$ \\
K. pachanoi & 0 & 3 and 4 & STZ & $2-10$ \\
K. pachanoi & $1-3$ & 4 & STZ & $2-10$ \\
K. rufescens & 0 & 2 and 3 & STZ and base of SAZ & $2-4$ \\
K. rufescens & $1-3$ & 3 and 4 & STZ and base of SAZ & $2-4$ \\
K. saltensis & $0-3$ & ABS & ABS & ABS \\
\hline
\end{tabular}

Note. Floral and trichome stages as in table 1 and "Results." STZ = stigmatic internal zone; SAZ = sterile apical appendage zone; ABS = glandular trichomes absent.

secretion phases (e.g., 1, 2, and 3) in styles of flowers in early developmental stages (floral stage 0 ). This indicates that trichomes in secretory phase or even early senescent trichomes are present before the female and, in some cases, the male floral stages begin before the corolla opens. These results coincide with other studies in that secretion of trichomes was completed before the opening of the corolla (Göpfert et al. 2005, 2009).

With respect to the nature of secretion, our results were positive for the presence of some sesquiterpene lactones in stylar glandular trichomes. Göpfert et al. (2005) have indicated for $H$. anuus that sesquiterpene lactones were secreted during the entire secretory stage of glandular trichomes. After this period, flavonoids were detected by observation of subcuticular chamber expansion and by the color, under fluorescence, of the flavonoid secretory products. Secretion of different products in different phases of trichome development was also reported, e.g., in Inula (Werker and Fahn 1981), although a similar process in Kaunia should be confirmed by further studies.

The presence of sesquiterpene lactones in stylar trichomes of Kaunia is not unlikely since these compounds, specifically Guaianolides and Germacranolides (Bohlmann et al. 1981; Maldonado et al. 2014a), have been previously detected in this genus
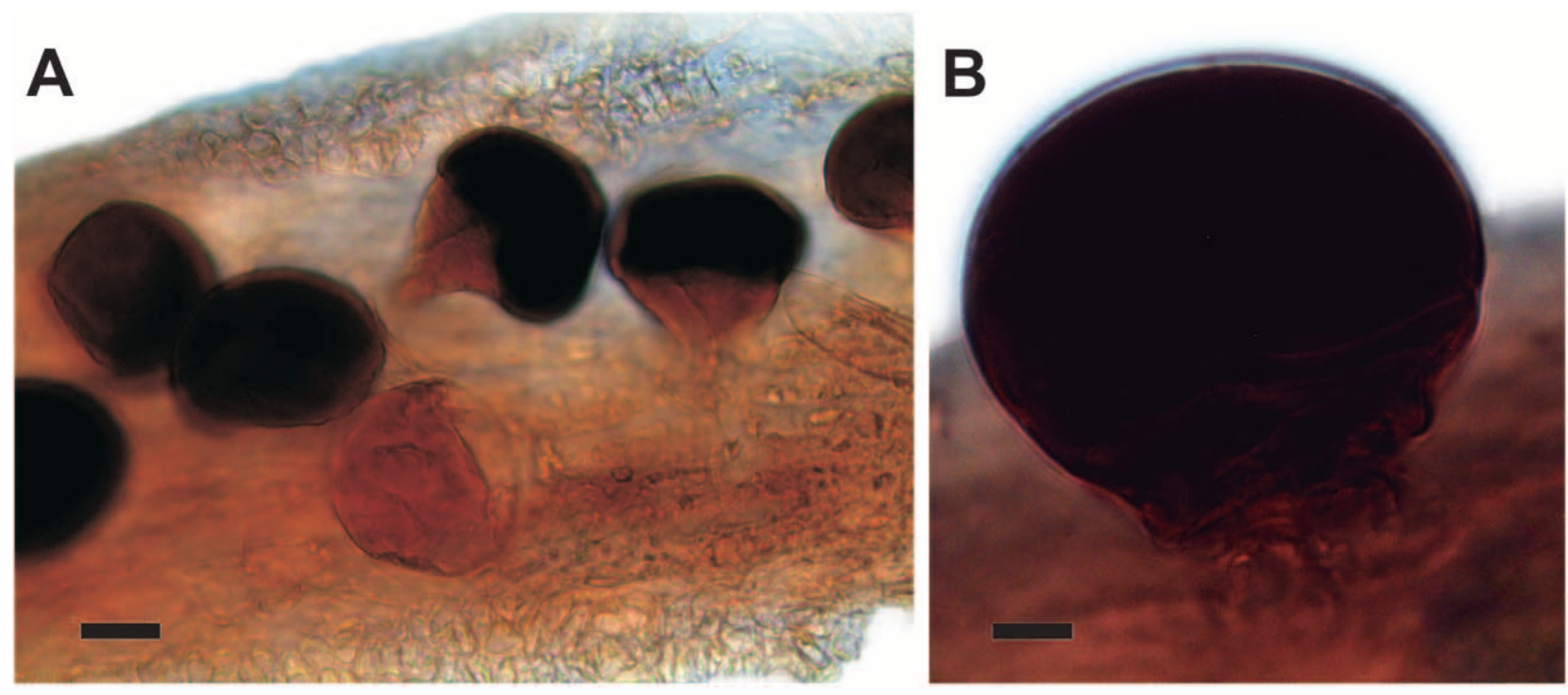

Fig. 5 Histochemical test for detecting sesquiterpene lactones in stylar glandular trichomes of Kaunia (images from LM). Dark red color indicates positive staining by concentrated sulfuric acid. $A$, Ventral face of style branch with stained trichomes. $B$, Glandular trichome showing stained basal cells and subcuticular chamber. Photographs: K. longipetiolata, Peyton 1144 (F). Scale bars: $A=18 \mu \mathrm{m}, B=8 \mu \mathrm{m}$. 
(Bohlmann et al. 1981; De Gutierrez et al. 1990; Rücker et al. 1997). Indeed, some of these compounds have demonstrated anticancer activity in vitro (Rücker et al. 2001; Maldonado et al. 2014a). As pointed out by Chadwick et al. (2013), sesquiterpenoids, specifically sesquiterpene lactones from Asteraceae, may play a highly significant role in human health, both as part of a balanced diet and as pharmaceutical agents due to their potential for the treatment of cardiovascular disease and cancer. Although it has been difficult to carry out the novo synthesis of some secondary metabolites produced by trichomes (Ferreira and Janick 1995), recent studies on transcriptional regulation of sesquiterpene synthase genes in glandular trichome cells have shed light on the biosynthesis and regulation of secondary metabolites (Göpfert et al. 2009). Our results provide a better understanding of glands of Kaunia, which, together with development of plant biotechnology, may improve the in situ production of trichome-localized secondary metabolites with potential medicinal uses.

The role of secondary metabolites in plant defense has been proposed by different authors (e.g., Levin 1973; Duke 1994; Rossi Monteiro et al. 2001; Elger et al. 2009). As pointed out by Handley et al. (2005), to reveal the mechanisms that contribute to plant resistance to herbivores is of fundamental interest for an understanding of the evolutionary dynamics of biotic interactions in natural systems but also for plant breeding and pest management in agriculture. Terpenoids, such as sesquiterpene lactones, have been pointed out as having antimicrobial activity (Kelsey et al. 1984; Duke 1991, 1994; Chadwick et al. 2013). In addition, according to Kelsey and Shafizadeh (1980), terpe- noids localized on plant surfaces as glandular trichomes may represent an immediate barrier to small herbivores, deterring feeding before extensive damage occurs. The presence of stylar glandular trichomes in secretory phase observed in early floral stages of Kaunia (even with closed corollas), together with the sesquiterpene lactones revealed in these glands, suggests a protective role of secretion in the developing styles of immature flowers. This agrees with statements by other authors who showed that most glandular trichomes are at the mature phase on very young structures (e.g., leaves [Rossi Monteiro et al. 2001], anthers of immature flowers [Göpfert et al. 2005]). Besides styles, the glandular trichomes of Kaunia are found on phyllaries, cypselae, and corolla lobes. In the frame of a potential protective role of secretion, glands on styles of Kaunia may be the most internal barrier to herbivores that flank outer floral structures during key floral stages, such as pollen and style development.

\section{Acknowledgments}

We would like to thank the curators of the F, GH, LP, LPB, $\mathrm{MO}$, and NY herbaria for the loan of specimens observed. We are also grateful to the editor, the anonymous reviewers, and Mariana Grossi for useful comments and suggestions on the manuscript. We would like to thank Ana C. Romero for help with the figure design. Funding for this research was supplied by Agencia Nacional de Promoción Científica y Tecnológica (ANPCyT) and Comisión Nacional de Investigaciones Científicas y Técnicas (CONICET).

\section{Appendix}

\section{Voucher Information}

Specimens analyzed for the study of stylar glandular trichomes of Kaunia. Information per species indicates collection site, collection number, acronyms of herbaria where vouchers are housed. Asterisks indicate specimens collected in the field and fixed in FAA.

K. camataquiensis (Hieron.) R. M. King \& H. Rob. Andrés Ibáñez, Santa Cruz de la Sierra, Bolivia, Viera Barreto et al. 44 *; Florida, Santa Cruz de la Sierra, Bolivia, Nee 49436 [F]; Oropeza, Chuquisaca, Bolivia, Ugent and Ugent 5140 [MO]. K. endyta (B. L. Rob.) R. M. King \& H. Rob. Nor Yungas, La Paz, Bolivia, Zardini 2013 [MO]; Sud Yungas, La Paz, Bolivia, Beck 12046 [LPB]; Sud Yungas, La Paz, Bolivia, Beck et al. 29751 [LP]; Sandia, Puno, Perú, Metcalf 30623 [MO]; Río Saturiapo, La Paz, Bolivia, Gentry and Foster 70869 [MO]. K. eucosmoides (B. L. Rob.) R. M. King \& H. Rob. La Mar Anco, Ayacucho, Perú, Killip and Smith 22179 [GH]. K. gynoxymorpha (Rusby ex B. L. Rob.) R. M. King \& H. Rob. Inquisivi, La Paz, Bolivia, Lewis 40446 [LPB]; Larecaja, La Paz, Bolivia, Buchtien 7550 [LP]. K. ignorata (Hieron.) R. M. King \& H. Rob. Caballero, Santa Cruz, Bolivia, Nee and Atha 50035 [NY]. K. lasiophthalma (Griseb.) R. M. King \& H. Rob. Capital, Tucumán, Argentina, Venturi 3529a [LP]; Charcas, Potosí, Bolivia, Torrico and Peca 482 [LP]. K. longipetiolata (Sch. Bip. Ex Rusby) R. M. King \& H. Rob. Comarapa, Santa Cruz de la Sierra, Bolivia, Viera Barreto et al. 58 *; Loja, Ecuador, Rose et al. 23229 [GH]; Quillabamba, Cuzco, Perú, B Peyton 1144 [F]; Santa Cruz, Cajamarca, Perú, Santisteban 159 [NY]. K. pachanoi (B. L. Rob) R. M. King \& H. Rob. Cañar, Ecuador, Jaramillo 9853 [NY]; Cañar, Ecuador, Ollgard et al. 57750 [NY]. K. rufescens (P. W. Lund ex DC.) R. M. King \& H. Rob. Caldas, Minas Gerais, Brasil, Edwall 16336 [GH]; Lauro Müller, Santa Catarina, Brasil, Reitz and Klein 8861 [NY]. K. saltensis (Hieron.) R. M. King \& H. Rob. Dr. Manuel Belgrano, Jujuy, Argentina, Cabrera 8143 [LP]; Valle Grande, Jujuy, Argentina, Fabris 5334 [LP].

\section{Literature Cited}

Anderberg AA, BG Baldwin, RG Bayer, J Breitwieser, C Jeffrey, MO Dillon, P Eldenäs, et al 2007 Compositae. Pages 61-588 in JW Kadereit, C Jeffrey, eds. The families and genera of vascular plants. Vol VIII. Springer, Berlin.

Andreucci AC, D Ciccarelli, I Desideri, AM Pagni 2008 Glandular hairs and secretory ducts of Matricaria chamomilla (Asteraceae): morphology and histochemistry. Ann Bot Fenn 45:11-18.
Bertea CM, A Voster, FWA Verstappen, M Maffei, J Beekwilder, HJ Bouwmeester 2006 Isoprenoid biosynthesis in Artemisia annua: cloning and heterologous expression of a germacrene A synthase from a glandular trichome cDNA library. Arch Biochem Biophys 448:3-12.

Bisio A, A Corallo, P Gastaldo, G Romussi, G Ciarallo, N Fontana, N de Tommasi, P Profumo 1999 Glandular hairs and secreted mate- 
rial in Salvia blepharophylla Brandegee ex Epling grown in Italy. Ann Bot 83:441-452.

Bohlmann F, W Kramp, RK Gupta, RM King, H Robinson 1981 Four guaianolides and other constituents from three Kaunia species. Phytochemistry 20:2375-2378.

Calabria LM, VP Emereciano, MT Scotti, TJ Mabry 2009 Secondary chemistry of Compositae. Pages 73-88 in VA Funk, A Susanna, TF Stuessy, R Bayer, eds. Systematics, evolution and biogeography of the Compositae. IAPT, Vienna.

Carpenter KJ 1999 Comparative morphology of disk floret trichomes of Encelia (Asteraceae: Heliantheae). PhD diss. Polytechnic University, Pomona, CA.

Chadwick M, H Trewin, F Gawthrop, C Wagstaff 2013 Sesquiterpenoids lactones: benefits to plants and people. Int J Mol Sci 14: 12780-12805.

Ciccarelli D, F Garbari, AM Pagni 2007 Glandular hairs on the ovary: a helpful character for Asteroideae (Asteraceae) taxonomy? Ann Bot Fenn 44:1-7.

De Gutierrez AN, EE Sigstad, CAN Catálan, AB Gutiérrez, W Herz 1990 Guaianolides from Kaunia lasiophthalma. Phytochemistry 29:1219-1225.

Duke SO 1991 Plant terpenoids as pesticides. Pages 269-296 in RF Keller, AT Tu, eds. Handbook of natural toxins. Vol 6. Toxicology of plant and fungal compounds. Dekker, New York.

1994 Commentary glandular trichomes: a focal point of chemical and structural interactions. Int J Plant Sci 155:617-620.

Elger A, DG Lemoine, M Fenner, ME Hanley 2009 Plant ontogeny and chemical defence: older seedlings are better defended. Oikos 118:767-773.

Emerenciano VP, JS Militão, CC Campos, P Romoff, MA Kaplan, M Zambon, AJ Brant 2001 Flavonoids as chemotaxonomic markers for Asteraceae. Biochem Syst Ecol 29:947-957.

Erbar C, P Leins 1995 Portioned pollen release and the syndromes of secondary pollen presentation in the Campanulales-Asterales complex). Flora 190:323-338.

Fahn A 1988 Secretory tissues in vascular plants. New Phytol 108: 229-257.

Ferreira JFS, J Janick 1995 Floral morphology of Artemisia annua with special reference to trichomes. Int J Plant Sci 156:807-815.

Geissman TA, TS Griffin 1971 Sesquiterpene lactones: acid-catalysed color reaction as an aid in structure determination. Phytochemistry 10:2475-2485.

Göpfert JC, N Heil, O Spring, J Conrad 2005 Cytological development and sesquiterpene lactone secretion in capitate glandular trichomes of sunflower. Plant Biol 7:148-155.

Göpfert JC, G MacNevin, DK Ro, O Spring 2009 Identification, functional characterization and developmental regulation of sesquiterpene synthases from sunflower capitates glandular trichomes. BMC Plant Biol 9:86-103.

Handley R, B Ekbom, J Agren 2005 Variation in trichome density and resistance against a specialist insect herbivore in natural populations of Arabidopsis thaliana. Ecol Entomol 30:284-292.

Harborne JB 1977 Flavonoid profiles in the Compositae. Pages 359384 in VH Heywood, JB Harborne, BL Turner, eds. The biology and chemistry of the Compositae. Vol 1. Academic Press, London.

Heinrich G, HW Pfeifhofer, E Stabentheiner, T Sawidis 2002 Glandular hairs of Siegesbeckia jorullensis Kunth (Asteraceae): morphology, histochemistry and composition of essential oil. Ann Bot 89:311-316

Hernández MP, L Katinas, AM Arambarri 2015 Taxonomic value of histochemical features of the style in early lineages of Asteraceae. Acta Bot Bras 29:575-585.

Herz W 1977 Sesquiterpen lactones in the Compositae. Pages 337357 in VH Heywood, JB Harborne, BL Turner, eds. The biology and chemistry of the Compositae. Vol 1. Academic Press, London.

$$
993 .
$$

Johansen DA 1940 Plant microtechnique. McGraw-Hill, New York.

Kelsey RG, GW Reynolds, E Rodriguez 1984 The chemistry of biologically active constituents secreted and stored in plant glandular trichomes. Pages 187-241 in E Rodriguez, PL Healey, I Mehta, eds. Biology and chemistry of plant trichomes. Plenum, New York.

Kelsey RG, F Shafizadeh 1980 Glandular trichomes and sesquiterpene lactones of Artemisia nova (Asteraceae). Biochem Syst Ecol 8:371-377.

King RM, H Robinson 1980 Studies in the Eupatorieae (Asteraceae). CCII. A new genus Kaunia. Phytologia 47:257-260.

1987 The genera of the Eupatorieae (Asteraceae). Monographs in Systematic Botany 22. Missouri Botanical Garden, St. Louis.

Langenheim JH 1994 Higher plants terpenoids: a phytocentric overview of their ecological roles. J Chem Ecol 20:1223-1279.

Lersten NR, JD Curtis 1988 Secretory reservoirs (ducts) of two kinds in giant ragweed (Ambrosia trifida; Asteraceae). Am J Bot 75:1313-1323.

Levin DA 1973 The role of trichomes in plant defense. Q Rev Biol 48:3-15.

Maldonado EM, D Svensson, SM Oredsson O Sterner 2014a Cytotoxic sesquiterpene lactones from Kaunia lasiophthalma Griseb. Sci Pharm 82:147-160.

2014b A novel cytotoxic terpenoid from the flowers of Kannia lasiophthalma Griseb. Phytochem Lett 8:105-108.

Metcalfe CR, L Chalk 1950 Anatomy of the Dicotyledons. Vol 2. Clarendon, Oxford.

Plos A, G Sancho, L Iharlegui 2011 Secretory structures of leaves of Ophryosporus Meyen (Asteraceae, Eupatorieae), a genus with medicinal properties. J Torrey Bot Soc 138:391-399.

Ramayya N 1962 Studies on the trichomes of some Compositae. I. General structure. Bull Bot Surv India 4:177-188.

Ramirez AM, G Stoopen, TR Menzel, R Gols, HJ Bouwmeester, M Dicke, MA Jongsmaa 2012 Bidirectional secretions from glandular trichomes of Pyrethrum enable immunization of seedlings. Plant Cell 24:4252-4265.

Robinson H 1999 Generic and subtribal classification of American Vernonieae. Smithson Contrib Bot 89:1-116.

Rossi Monteiro W, M de Moraes Castro, SC Mazzoni-Viveiros, PG Mahlberg 2001 Development and some histochemical aspects of foliar glandular trichomes of Stevia rebaudiana (Bert.) Bert.-Asteraceae. Bras J Bot 24:349-357.

Rücker G, K Heiden, E Schenkel 2001 Antitumor-active lactones from Kaunia rufescens and Eupatorium cannabinum. J Indian Inst Sci 81:333-334.

Rücker G, EP Schenkel, D Manns, R Mayer, BM Hausen, K Heiden 1997 Allergenic sesquiterpene lactones from Eupatorium cannabinum L. and Kaunia rufescens (Lund ex de Candolle). Nat Toxins 5: 223-227.

Seaman FC 1982 Sesquiterpene lactones as taxonomic characters in the Asteraceae. Bot Rev 48:121-594.

Seaman FC, NH Fischer, TF Stuessy 1980 Systematic implications of sesquiterpene lactones in the subtribe Melampodiinae. Biochem Syst Ecol 8:263-271.

Taleb-Contini SH, MJ Salvador, JMF Balanco, S Albuquerque, DCR Oliveira 2004 Antiprotozoal effect of crude extracts and flavonoids isolated from Chromolaena hirsuta (Asteraceae). Phytother Res 18: 250-254.

Taleb-Contini SH, K Schorr, FB Da Costa, DC Rodrigues de Oliveira 2007 Detection of flavonoids in glandular trichomes of Chromolaena species (Eupatorieae, Asteraceae) by reversed-phase high-performance liquid chromatography. Braz J Pharm Sci 43:315-321.

Tateo F, M Bononi, MG Mariotti, L Cornara, G Serrato-Valenti 2001 Trichomes on vegetative and reproductive organs of Stevia 
rebaudiana (Asteraceae): structure and secretory products. Plant Biosyst 135:25-37.

Tetley U 1925 The secretory system of the roots of the Compositae. New Phytol 24:138-162.

Tissier A 2012 Glandular trichomes: what comes after expressed sequence tags? Plant J 70:51-68.

Via do Pico GM, AJ Vega, M Dematteis 2016 Systematic consideration of floral microcharacters of the South American genus Chrysolaena (Vernonieae, Asteraceae). Syst Biodivers 14:224-243.
Werker E 1993 Function of essential oil-secreting glandular hairs in aromatic plants of the Lamiaceae: a review. Flavour Frag J 8:249255.

2000 Trichome diversity and development. Pages 1-35 in DL Hallahan, JC Gray, eds. Advances in botanical research incorporating advances in plant pathology. Vol 31. Plant trichomes. Academic Press, San Diego, CA.

Werker E, A Fahn 1981 Secretory hairs of Inula viscosa (L.) Ait.: development, ultrastructure, and secretion. Bot Gaz 142:461-476. 